\title{
Effect of alpha-7 nicotinic acetylcholine receptor activation on beta-amyloid induced recognition memory impairment. Possible role of neurovascular function ${ }^{1}$
}

\author{
Saeed Sadigh-Eteghad ${ }^{\mathrm{I}}$, Javad Mahmoudi ${ }^{\mathrm{II}}$, Shirin Babri ${ }^{\mathrm{III}}$, Mahnaz Talebi ${ }^{\mathrm{IV}}$ \\ DOI: http://dx.doi.org/10.1590/S0102-865020150110000003 \\ IPhD, Neurosciences Research Center (NSRC), Tabriz University of Medical Sciences, Tabriz, Iran. Acquisition, analysis and interpretation of data; \\ manuscript writing. \\ IIAssociate Professor, NSRC, Tabriz University of Medical Sciences, Tabriz, Iran. Critical revision. \\ IIIFull Professor, NSRC, Tabriz University of Medical Sciences, Tabriz, Iran. Critical revision.

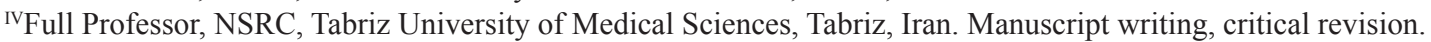

\begin{abstract}
PURPOSE: To evaluate the effects of PHA-543613 ( $\alpha 7$-nAChR agonist) and galantamine (acetylcholinesterase inhibitor (AChEI)) on recognition memory and neurovascular coupling (NVC) response in beta-amyloid (A $\beta)_{25-35}$-treated mice.

METHODS: PHA-543613 (1 mg/kg, i.p.), and galantamine (3 mg/kg, s.c.), effects were tested in A $\beta_{25-35}$ mice model of AD. $\alpha 7$-nAChR antagonist, methyllycaconitine (MLA) (1 mg/kg, i.p.), was used for evaluation of receptor blockade effects. Recognition memory in animals was assessed by the novel object recognition (NOR) task. NVC response was analyzed by laser-doppler flow meter in barrel cortex by whisker stimulation method.

RESULTS: Both, PHA-543613 and galantamine improve recognition memory in A $\beta$-treated animals. However, the advantageous effects of PHA-543613 were significantly higher than galantamine. Also, pretreatment with MLA reversed both galantamine and PHA543613 effects on NOR. Impaired NVC response in AD animals was improved by PHA-543613 and galantamine. However, MLA pretreatment disrupts this function.

CONCLUSION: Activation of $\alpha 7$-nAChR improved recognition memory possible through enhancement of neurovascular response in Alzheimer's disease in animals.

Key words: Amyloid beta-Peptides. Recognition. Receptors, Nicotinic. Mice.
\end{abstract}




\section{Introduction}

Alzheimer's disease (AD) is a neurodegenerative disorder and most prevalent form of dementia which is characterized by amyloid beta $(\mathrm{A} \beta)$ accumulation in neuronal structures of the brain and cholinergic dysfunction ${ }^{1}$. In this way, the nicotinic acetylcholine receptor (nAChR) as a key component of cholinergic function plays axial role in disease progression ${ }^{2}$. Among nAChR subunits, homomeric $\alpha 7$ receptor seems to have an important role in cognitive-related processes ${ }^{3}$. It is the most abundant nAChR subtype in the hippocampus, cortex and hypothalamus of the mammalian brain ${ }^{4}$. Studies show that $A \beta$ may cause cholinergic dysfunction through affecting $\alpha 7-n A_{C h R}^{5}$. Moreover, $\alpha 7-n A C h R$ activation decreases $A \beta$-induced neurotoxicity ${ }^{6}$. Studies have shown that $\alpha 7$-nAChR activation may represent a therapeutic strategy for AD-related cognitive impairments ${ }^{7}$.

Also, the cholinergic-vascular hypothesis, suggests that the loss of cholinergic vascular innervation is responsible for the impairment of cerebral blood flow (CBF) in $\mathrm{AD}^{8}$. The tight coupling between neuronal activity and CBF is known as functional hyperemia or neurovascular coupling (NVC) which is altered both in $\mathrm{AD}$ patients and animal models ${ }^{9} . \mathrm{A} \beta$ is responsible for impairment of cerebrovascular auto-regulation and NVC response ${ }^{10}$. Also, $A \beta$ could attenuate cerebral hemostasis by blocking $\alpha 7-n A C h R s$ and activation of this receptor could improve impaired cerebral hemodynamic and NVC response in $\mathrm{AD}^{11}$.

PHA-543613 is a potent and selective $\alpha 7-n A C h R$ agonist with ability of brain penetration. However, there are limited reports about its exact procognitive mechanisms. Hence, this study was conducted to assess the possible effect of this molecule on recognition memory in $\mathrm{A} \beta$-treated animals and possible role of NVC response in this matter.

\section{Methods}

\section{Experimental animals}

The experimental procedures were approved by regional ethics committee of Tabriz University of Medical Sciences (TUOMS) (code number: 5.4.6251).

$\mathrm{BALB} / \mathrm{c}$ male mice weighing 25-30 grams were obtained (total number=105) from Razi Institute Laboratory Animal Care Center (Karaj, Iran). Before and during the study, animals were housed in standard cages (five animal per cage) under controlled conditions (12/12 h light/dark cycle starting at 7:00 AM and temperature of $25 \pm 2^{\circ} \mathrm{C}$ ) with access to water and standard pellet food ad libitum.

\section{Drugs and chemicals}

Galantamine (Acetylcholinesterase inhibitor (AChEI)) was obtained from Tehran Darou Pharmaceutical Co (Tehran, Iran). Methyllycaconitine (MLA) and $[1 \alpha, 4(S), 6 \beta, 14 \alpha, 16 \beta]-20-$ Ethyl-1,6,14,16-tetramethoxy-4-[[[2-(3-methyl-2,5-dioxo-1pyrrolidinyl) benzoyl]oxy]methyl] aconitane-7,8-diol citrate ( $\alpha 7$ nAChR selective antagonist) (ab120072) were purchased from Abcam (Cambridge, UK). Other chemicals including $A \beta_{25-35}$ peptide and PHA-543613 (N-[(3R)-1-Azabicyclo [2.2.2] oct-3yl] furo [2, 3-c] pyridine-5-carboxamide) ( $\alpha 7-n A C h R$ selective agonist) (PZ0135) were purchased from Sigma-Aldrich (St Louis, MO, USA).

\section{Drug treatments}

Drugs and/or vehicle were injected by intraperitoneal route (i.p.), except galantamine that was administrated subcutaneously (s.c.). Control group did not receive any treatment during the study. Seperate groups of $A \beta_{25-35}$-injected mice received vehicle, PHA-543613 (1 mg/kg), galantamine (3 mg/kg) or concomitant injection of MLA (3 mg/kg) with galantamine (3 mg/kg) or PHA$543613(1 \mathrm{mg} / \mathrm{kg})$ for 14 consecutive days post-surgery procedure (time line of treatments illustrated in Figure 1). The dosages and paradigms of injections were chosen on the basis of previous studies $^{12-14}$.

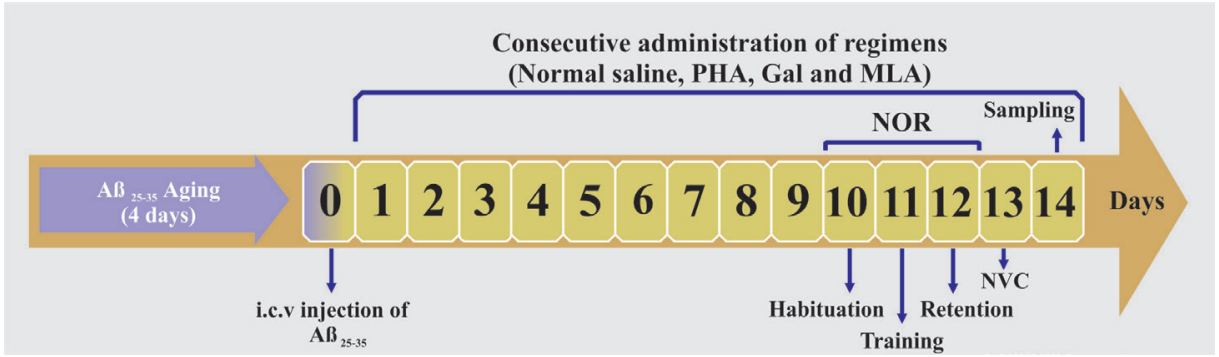

FIGURE 1 - Time line of treatments and tests. PHA (PHA-543613); Gal (galantamine); MLA (methyllycaconitine); A $\beta_{25-35}$ (beta-amyloid ${ }_{25-35}$ ); NOR (novel object recognition test); NVC (neurovascular coupling response evaluation). 


\section{Intracerebroventricular (i.c.v.) injection of $A \beta_{25-35}$ peptides}

$\mathrm{A} \beta$ administration and model preparation were done according to previously described method ${ }^{15}$. Briefly, $A \beta_{25-35}$ peptide was dissolved in phosphate buffer saline (PBS) at a concentration of $2 \mathrm{mg} / \mathrm{ml}$ and was incubated for peptide aging or aggregation at $37^{\circ} \mathrm{C}$ for four days.

Animals were anesthetized with a combination of ketamine and xylazine (90 and10 mg/kg, i.p., respectively). A $\beta_{25-35}(10 \mathrm{nmol} /$ mice) was infused stereotaxically (anteroposterior $(\mathrm{AP})=-0.7$, mediolateral $(\mathrm{ML})=1.2 \mathrm{~mm}$ and dorsoventral $(\mathrm{DV})=2)$ based on the mouse brain in stereotaxic coordinates ${ }^{16}$. Body temperature was maintained at $36.5 \pm 0.5^{\circ} \mathrm{C}$. Sham operated animals were subjected to the same procedure, except same volume vehicle was injected. All mice were individually housed following two days of surgery.

Administration of saline (i.c.v.) did not have significant effect on animals' survival or function in comparison to control (vehicle via i.p. route) group. Therefore, the results of sham group were not showed in the results section.

\section{Novel object recognition test protocol}

\section{Test apparatus and condition}

The test apparatus was a plexiglas open-field box $(33 \times 33 \times 20 \mathrm{~cm})$. The box was placed in an acoustically-isolated room and light was provided by overhead lighting (15 lux). We used common objects that were different in shape and texture, however, the objects were counterbalanced in complexity. Direction of animal nose to the object (distance of $\leq 2 \mathrm{~cm}$ ) and rearing up against the object to investigation were considered as exploration. After each trial, the arena and objects were cleaned with a $70 \%$ ethanol solution to eliminate the presence of any olfactory cues. All sessions were carried out during the morning (from 09:00). Data were acquired through a video camera that was fixed above the center of the task apparatus. All observations were done by an experimenter that was unaware of the entity of experimentations.

\section{Habituation session}

The habituation session of the NOR started 1 day prior to the training step. Before testing, animals were transferred to the test room and were placed there for 15 minutes for acclimation. Then, each mouse was placed in the box for habituation in the absence of objects for $10 \mathrm{~min}$. Moreover, locomotor activity was recorded during the habituation session.

\section{Training session}

One day after the habituation session, the animals were subjected to a training session. During the training, two identical objects ( $\mathrm{A}$ and $\mathrm{A}^{\prime}$ ) were placed in the box, $12 \mathrm{~cm}$ from lateral walls. Then, each animal was placed in the middle of the box and the total time spent to explore both objects was recorded over 10 minutes.

\section{$\underline{\text { Retention session }}$}

For recognition memory evaluation, the animals were subjected to a single retention session the next day after the training trial. For this purpose, the animals were returned into the same task, but one of the familiar objects applied during the training session was replaced by a novel object B. Cognitive function was measured by exploratory preference, which was calculated by percent of time spent exploring each of the same objects or the novel object in the training and retention sessions, over the total time spent exploring both objects.

\section{Measurement of NVC response}

Neuronal activity-evoked CBF response provides an index for NVC. For evaluation of this response, on the day after behavioral testing, the $\mathrm{rCBF}$ on the surface of the right barrel cortex was measured using $0.6 \mathrm{~mm}$ diameter probe of Laser Doppler Flow meter (LDF) (Laserflo, Vasamedics, USA). In brief, animals were anaesthetized with $2 \%$ isoflurane, which was administered in a mixture of $70 \% \mathrm{~N}_{2}$ and $30 \% \mathrm{O}_{2}$. Mice were mounted in a stereotaxic frame. Because CBF measurements by LDF can vary depending on the monitoring site, the probe was placed at the same stereotaxic coordinates based on the mouse brain in stereotaxic coordinates $\mathrm{AP}=-1.8 \mathrm{~mm}$ and $\mathrm{ML}=+2.5 \mathrm{~mm}^{16}$. The skull was thinned until being translucent using a dental drill. The tip of LDF was positioned on the thinned skull perpendicular to the surface of the brain. While we avoided large blood vessel areas we waited until the stable baseline was recorded for 10 minutes. Contralateral vibrissae were cut to an equal length of $0.5 \mathrm{~cm}$ and stimulated using a cotton swab. Stimulations (3-6 stimulations, 20 seconds at $8-10 \mathrm{~Hz}$ ) were recorded, with four to six recordings that were acquired every $30-40$ seconds and were averaged for each mouse. CBF change was defined as percentage increase relative to the baseline. The rectal temperature was maintained at $36.5 \pm 0.5^{\circ} \mathrm{C}$ by placing the animals on a heating pad.

\section{Statistical analysis}

Descriptive data were defined as means \pm SEM. Comparison of different groups was carried out by two-way or 
one-way ANOVA followed by post hoc Tukey test. T-test analysis was used to two-group comparison. All analyses were performed using IBM SPSS Statistics software (version 22 for Windows; SPSS Inc., Chicago, IL, USA). In all comparisons, $\mathrm{p}<0.05$ was considered significant.

\section{Results}

\section{Locomotor activity}

The locomotor activity was recorded during the NOR habituation session. Treatments in used doses had no significant effect on locomotor activity in different groups $\left[F_{(4,70)}=0.05\right.$, $p>0.05]$.

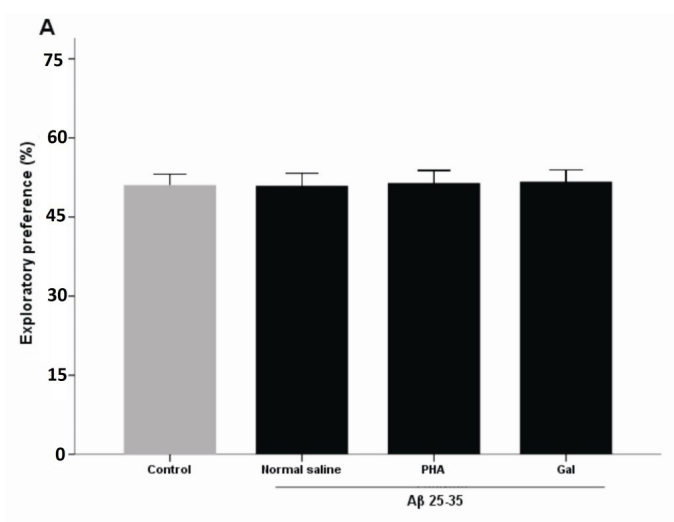

\section{Effect of treatments on recognition memory}

Treatments did not have any effect on exploratory preference for the objects in the training session $\left[F_{(4,70)}=0.07\right.$, $p>0.05]$. However, in the retention session, there was a statistically significant difference between groups as determined by one-way $\operatorname{ANOVA}\left(F_{(4,70)}=25.89, p<0.001\right)$.

Post hoc analysis of retention session data revealed that, $\mathrm{A} \beta$ significantly reduced the exploratory preference for a novel object in comparison to control group $(p<0.001)$ and treatment with PHA-543613 and galantamine significantly improved A $\beta$-induced recognition memory impairment $(p<0.001)$. Also, in comparison to the control group, PHA-543613-treated AD animals did not have significant difference $(p>0.05)$ in exploratory preference, but in the galantamine group it was significantly lower $(p<0.05)$ (Figure 2).

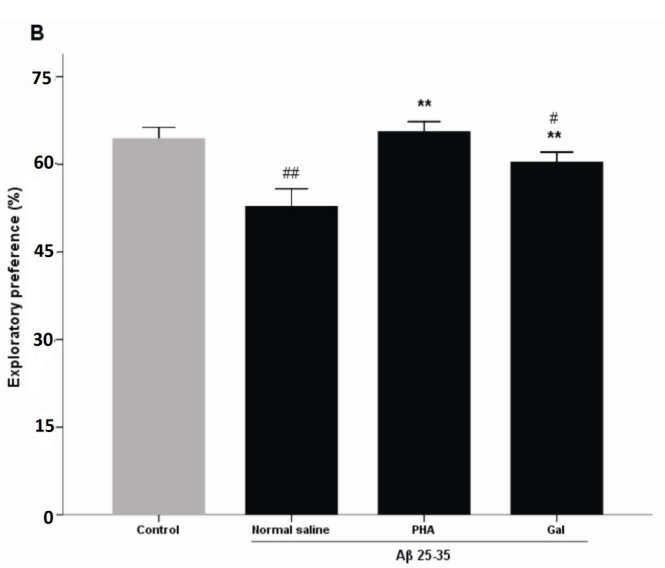

FIGURE 2 - Percentage of exploratory preference in training (A) and retention (B) sessions of NOR test in different groups (n=15) Each bar represents the mean \pm SEM. ${ }^{* *} p<0.001$ compared with the normal saline treated AD mice. ${ }^{\# \#} p<0.001,{ }^{*} p<0.05$ compared with the control group. PHA (PHA543613); Gal (galantamine); $\mathrm{A} \beta_{25-35}$ (beta-amyloid ${ }_{25-35}$ ).

\section{Involvement of $\alpha 7-n A C h R$ in the recognition memory}

The involvement of $\alpha 7-n A C h R s$ in PHA-543613 or galantamine-induced recognition memory enhancement was investigated by pretreatment with normal saline or MLA. A twoway ANOVA revealed significant differences of pretreatment $\left[F_{(1,}\right.$ $\left.{ }_{56)}=122.67, p<0.001\right]$ and treatment $\times$ pretreatment interaction $[F$ $\left.{ }_{(3,56)}=49.03, p<0.001\right]$, but not treatment $\left[F_{(1,56)}=0.51, p>0.05\right]$.

Pretreatment with MLA significantly prevented the improving effects of PHA-543613 on the impairment of recognition memory in $\mathrm{A} \beta$-treated mice $(p<0.001)$. Furthermore, galantamine effect on NOR performances of $\mathrm{AD}$-animals could be abolished by the pretreatment with MLA $(p<0.001)$. Pretreatment with normal saline, had no effect on the treatments results. $\alpha 7$ nAChR blockage in galantamine group had a lower effect on recognition memory in comparison to blockage of that receptor in the PHA-543613 group ( $p<0.05)$ (Figure 3).

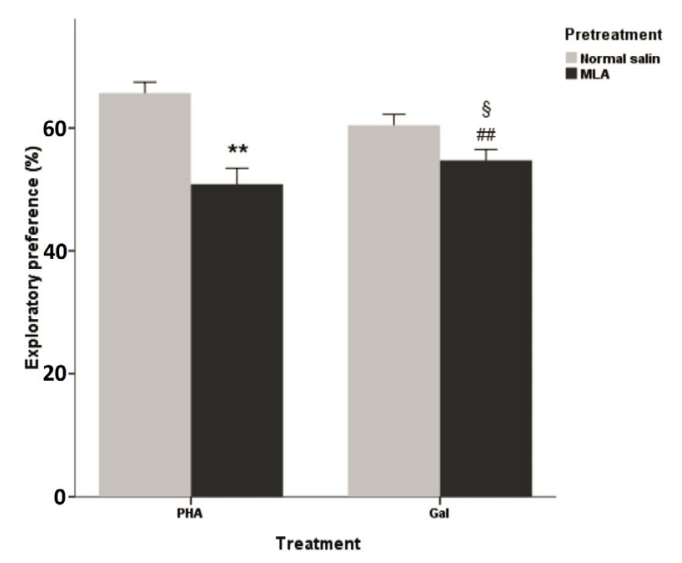

FIGURE 3 - Effect of pretreatment of AD mice with normal saline or MLA (3 mg/kg, i.p.) on the PHA (1 mg/kg, i.p.) or Gal (3 mg/ $/ \mathrm{kg}$, s.c.) induced cognitive effects in retention session of NOR test. $(n=15)$ Each bar represents the mean \pm SEM. ${ }^{* *} p<0.001$, ${ }^{\# \#} p<0.001$ and ${ }^{\S} p<0.05$ compared with the normal saline + PHA (1 mg/kg, i.p.), normal saline + Gal (3 mg/kg, s.c.) and MLA (3 mg/kg, i.p.) + PHA (1 mg/kg, i.p.) received groups, respectively. PHA (PHA-543613); Gal (galantamine); MLA (methyllycaconitine); $A \beta_{25-35}$ (beta-amyloid ${ }_{25-35}$ ). 


\section{Effect of treatments on NVC response}

There was a significant difference in NVC response between groups as determined by one-way ANOVA $\left[F_{(3,28)}=56.6\right.$, $p<0.001]$. Post hoc analysis revealed that NVC response in AD animals was significantly lower as compared with control group $(p<0.001)$. PHA-543613 and galantamine treatment significantly increased NVC response in A $\beta$-treated mice $(p<0.001)$ (Figure 4).

\section{$\mathbf{A}$}
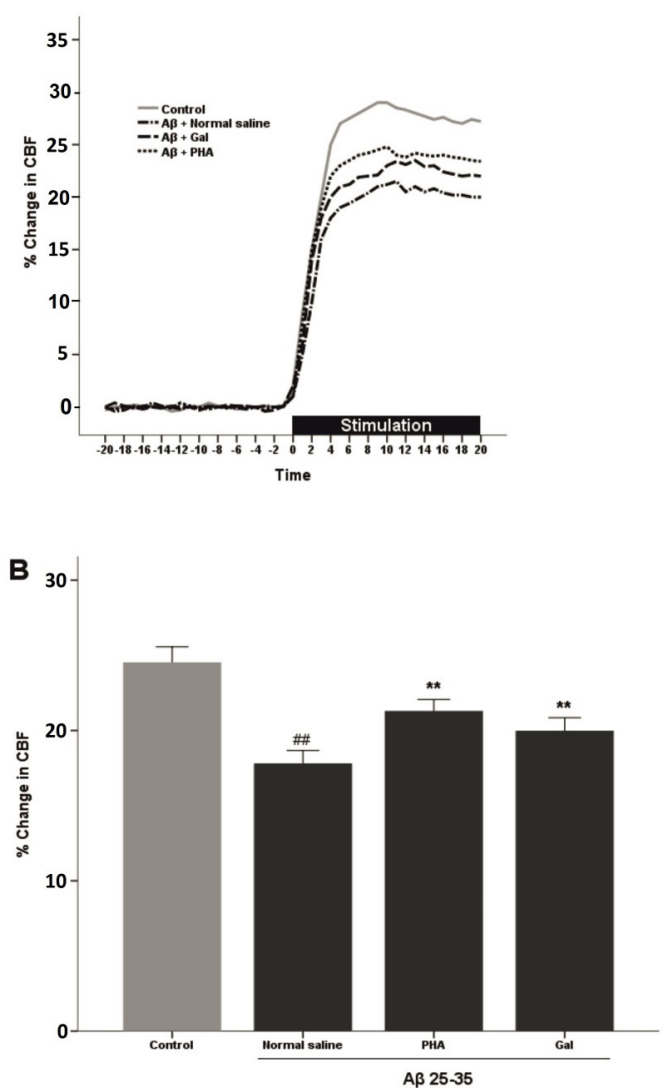

FIGURE 4 - (A) Time-response curves for averaged CBF. These data were normalized to baseline level (20 s before stimulation). (B) The percentage change in CBF calculated as averaged values during whisker stimulation $(20 \mathrm{~s})(\mathrm{n}=8)$. Each bar represents the mean \pm SEM. ${ }^{* *} p<0.001$ compared with the normal saline treated AD mice. ${ }^{\# \#} p<0.001$ compared with the control group. PHA (PHA-543613); Gal (galantamine); $\mathrm{A} \beta_{25-35}$ (beta-amyloid $25-35$ ).

\section{Involvement of $\alpha 7-n A C h R$ on $N V C$ response}

Pretreatment with normal saline or MLA in PHA-543613 or galantamine-received $\mathrm{AD}$ animals showed that $\alpha 7-\mathrm{nAChR}$ contributed to NVC response. A two-way ANOVA revealed significant differences of pretreatment $\left[F_{(1,28)}=67.8, p<0.001\right]$ and treatment $\times$ pretreatment interaction $\left[F_{(1.28)}=11.7, p<0.01\right]$, but not treatment $\left[F_{(1,28)}=1.81, p>0.05\right]$.
MLA significantly prevented the improving effects of PHA-543613 on NVC response in AD animals $(p<0.001)$. Moreover, the galantamine effect was abolished by the pretreatment with MLA, too $(p<0.05)$ (Figure 5).

A
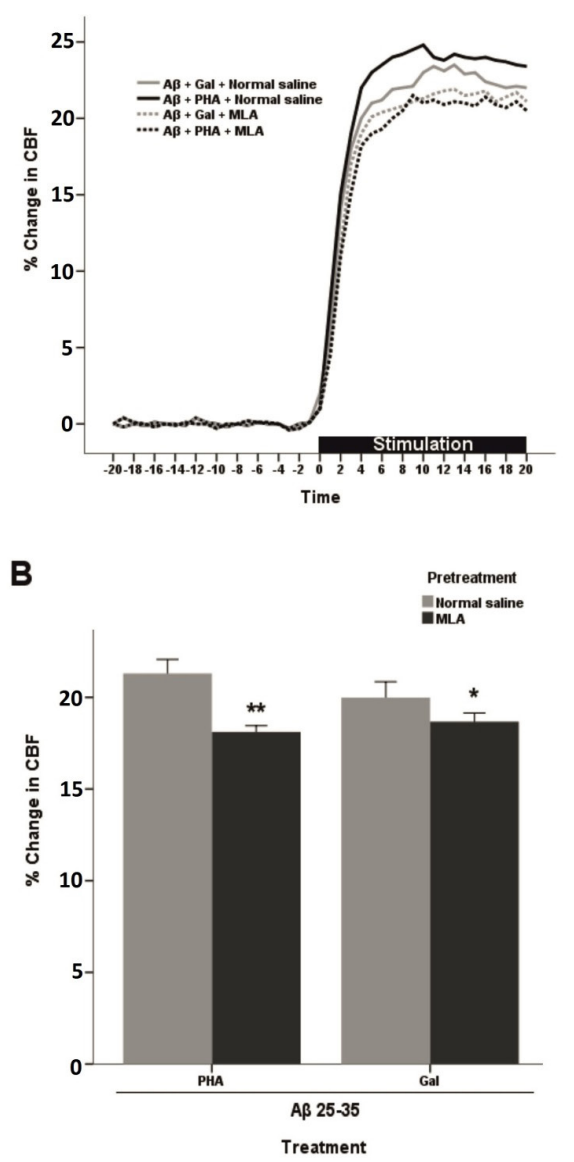

FIGURE 5 - Effect of pretreatment of AD mice with normal saline or MLA (3 mg/kg, i.p.) on the PHA (1 mg/kg, i.p.) or Gal (3 mg/kg, s.c.) induced effects on functional hyperemia. (A) Time-response curves for averaged CBF. These data were normalized to baseline level (20 s before stimulation). (B) The percentage change in CBF calculated as averaged values during whisker stimulation $(20 \mathrm{~s})(\mathrm{n}=8)$. Each bar represents the mean \pm SEM. ${ }^{* *} p<0.001$ and ${ }^{*} p<0.05$ compared with the normal saline + PHA (1 mg/kg, i.p.) and normal saline $+\mathrm{Gal}(3 \mathrm{mg} / \mathrm{kg}$, s.c. $)$ received groups, respectively. PHA (PHA-543613); Gal (galantamine); MLA (methyllycaconitine); $\mathrm{A} \beta_{25-35}$ (beta-amyloid ${ }_{25-35}$ ).

\section{Discussion}

The main findings of this study showed that activation of $\alpha 7$-nAChRs is able to improve $\mathrm{A} \beta_{25-35}$-induced recognition memory dysfunction possibly through modulation of $\mathrm{NVC}$ response. Aspects of $\mathrm{AD}$ can be mimicked by i.c.v. administration of $A \beta$ peptides in the rodent brain ${ }^{1}$.

In this study, we observed that single i.c.v. administration 
of $10 \mathrm{nmol} \mathrm{A} \beta_{25-35}$ could impair recognition memory in mice. This result is consistent with the findings of other studies ${ }^{1,15,17}$.

The NOR task was selected for recognition memory evaluations in this study. The NOR test evaluates recognition memory in rodents ${ }^{18}$. Recognition memory is strongly correlated with hippocampal and cortical functional integrity in both rodents' and primates' brains ${ }^{19}$. Moreover, both cortical and hippocampal dysfunctions affect NOR paradigm results ${ }^{18}$. These compartments of the brain are well-documented to be adversely affected in aging and $\mathrm{AD}^{20}$. Also, the NOR task is a simple and non-stressful method in which external motivations are not necessary, so it is a suitable method for evaluation of recognition memory in aged or $\mathrm{AD}$ animals ${ }^{18}$.

According to the results, significant enhancement was seen in the exploratory preference of novel object in PHA-543613 and galantamine-received AD animals. This showed that both PHA-543613 and galantamine could improve recognition memory in A $\beta$-treated mice. However, in NOR task performance, the effect of galantamine (as an AChEI) was lower than PHA-543613 (as a selective agonist of receptor) which showed the importance of $\alpha 7-n A C h R$ selective activation versus general acetylcholine increasing in improvement of recognition memory in AD-animals.

Interestingly, PHA-543613 or galantamine-induced enhancement in recognition memory is completely or partially blocked by MLA pretreatment. It showed that $\alpha 7-n A C h R$ plays a cardinal role not only in PHA-543613, but also in galantamine procognitive effects.

There is very limited information about procognitive effects of PHA-543613. Wishka et al. first synthesized the PHA543613 and evaluated its cognitive effects on normal rats ${ }^{12}$. Our recently- published paper showed its ameliorative effects on spatial memory in A $\beta$-treated animals ${ }^{15}$. Bali et al. described PHA543613's procognitive effects on T-maze in the scopolamineinduced memory impairment model ${ }^{7}$.

Activation of $\alpha 7-\mathrm{nAChR}$ by various agonists showed improvement in recognition memory in different studies. In the Roncarati et al. study, SEN12333 ( $\alpha 7$-nAChR agonist) prevented scopolamine-induced deficit in a recognition test ${ }^{21}$. In another study, Boess et al. ${ }^{22}$, showed that the $\alpha 7-n$ AChR agonist ABBF improves social recognition memory in rats. Also, a study by McLean et al. showed that, recognition deficits in NOR could be attenuated by PNU-282987, a full agonist of $\alpha 7-n \mathrm{AChR}^{23}$.

According to a study by Tinsley et al. ${ }^{24}$, blockade of $\alpha 7$ nAChR by MLA could significantly impair object recognition memory. In a study by Pichat et al., acute treatment with SSR180711 improved recognition memory in object recognition tasks in rats and it was reversed by the $\alpha 7-n A C h R$ antagonist MLA $^{14}$. Callahan et al. ${ }^{25}$, assessed recognition memory using the
NOR in aged rats. They showed pretreatment with MLA reversed the recognition memory enhancement produced by the donepezil.

Evidence showed that $A \beta$ could impair NVC response in $\mathrm{AD}$ patients and experimental models ${ }^{26}$. In our study, $A \beta$-treated mice showed impaired NVC response during whisker stimulation. Also, in Badhwar et al study impaired NVC response was seen in APP mice in the same situation ${ }^{27}$. Moreover, it has been shown that topical superfusion of soluble $A \beta$ on the mouse neocortex attenuated $\mathrm{CBF}$ increase evoked by whisker stimulation ${ }^{17}$. In this study, PHA-543613 and galantamine treatment significantly increased NVC response in A $\beta$-treated mice and MLA pretreatment completely or partially prevented their improving effects. Si et $a l .^{28}$, hypothesized that activation of $\alpha 7-n A C h R s$ on cerebral perivascular sympathetic nerves leads to vasodilation and blockade of this receptor which reverses the effect. Rosengarten et $a l .{ }^{29}$ found that impaired NVC response was recovered under AChEI treatment in AD patients. Moreover, according to Bar et $a l{ }^{30}$, galantamine treatment improved vascular reactivity in AD. Overall, the cholinergic system, especially $\alpha 7$-nAChRs, plays a curtail role in neurovascular function in $\mathrm{AD}^{8,26}$.

\section{Conclusion}

Activation of $\alpha 7-n A C h R$ improved recognition memory possible through enhancement of neurovascular response in Alzheimer's disease in animals

\section{References}

1. Sadigh-Eteghad S, Sabermarouf B, Majdi A, Talebi M, Farhoudi M, Mahmoudi J. Amyloid-Beta: a crucial factor in Alzheimer's disease. Med Princ Pract. 2015;24(1):1-10. PMID: 25471398.

2. Gotti C, Clementi F, Fornari A, Gaimarri A, Guiducci S, Manfredi I, Moretti M, Pedrazzi P, Pucci L, Zoli M.. Structural and functional diversity of native brain neuronal nicotinic receptors. Biochem Pharmacol. 2009;78(7):703-11. PMID: 19481063.

3. Wallace TL, Porter RH. Targeting the nicotinic alpha7 acetylcholine receptor to enhance cognition in disease. Biochem Pharmacol. 2011;82(8):891-903. PMID: 21741954.

4. Hajos M, Rogers BN. Targeting $\alpha 7$ nicotinic acetylcholine receptors in the treatment of schizophrenia. Curr Pharm Des. 2010;16(5):53854. doi: 10.2174/138161210790361434.

5. Sadigh-Eteghad S, Talebi M, Farhoudi M, Golzari SE, Sabermarouf B, Mahmoudi J. Beta-amyloid exhibits antagonistic effects on alpha 7 nicotinic acetylcholine receptors in orchestrated manner. J Med Hypotheses Ideas. 2014;8(2):49-52. doi: 10.1016/j. jmhi.2014.01.001.

6. Hernandez CM, Kayed R, Zheng H, Sweatt JD, Dineley KT. Loss of $\alpha 7$ nicotinic receptors enhances $\beta$-amyloid oligomer accumulation, exacerbating early-stage cognitive decline and septohippocampal pathology in a mouse model of Alzheimer's disease. J Neurosci. 2010;30(7):2442-53. doi: 10.1523/jnurosci.5038-09.2010.

7. Bali ZK, Inkeller J, Csurgyok R, Bruszt N, Horvath H, Hernadi I. Differential effects of alpha7 nicotinic receptor agonist 
PHA-543613 on spatial memory performance of rats in two distinct pharmacological dementia models. Behav Brain Res. 2014;278C:404-10. PMID: 25447295.

8. Van Beek AH, Claassen JA. The cerebrovascular role of the cholinergic neural system in Alzheimer's disease. Behav Brain Res. 2011;221(2):537-42. PMID: 20060023.

9. Park L, Anrather J, Forster C, Kazama K, Carlson GA, Iadecola C. Abeta-induced vascular oxidative stress and attenuation of functional hyperemia in mouse somatosensory cortex. J Cereb Blood Flow Metab. 2004;24(3):334-42. PMID: 15091114.

10. Niwa K, Kazama K, Younkin SG, Carlson GA, Iadecola C. Alterations in cerebral blood flow and glucose utilization in mice overexpressing the amyloid precursor protein. Neurobiol Dis. 2002;9(1):61-8. PMID: 11848685.

11. Rosengarten B, Paulsen S, Burr O, Kaps M. Neurovascular coupling in Alzheimer patients: effect of acetylcholine-esterase inhibitors. Neurobiol Aging. 2009;30(12):1918-23. PMID: 18395940.

12. Wishka DG, Walker DP, Yates KM, Reitz SC, Jia S, Myers JK, Olson KL, Jacobsen EJ, Wolfe ML, Groppi VE, Hanchar AJ, Thornburgh BA, Cortes-Burgos LA, Wong EH, Staton BA, Raub TJ, Higdon NR, Wall TM, Hurst RS, Walters RR, Hoffmann WE, Hajos M, Franklin S, Carey G, Gold LH, Cook KK, Sands SB, Zhao SX, Soglia JR, Kalgutkar AS, Arneric SP, Rogers BN. Discovery of N-[(3R)-1azabicyclo[2.2.2]oct-3-yl]furo[2,3-c]pyridine-5-carboxamide, an agonist of the alpha7 nicotinic acetylcholine receptor, for the potential treatment of cognitive deficits in schizophrenia: synthesis and structure--activity relationship. J Med Chem. 2006;49(14):442536. PMID: 16821801 .

13. Wang D, Noda Y, Zhou Y, Mouri A, Mizoguchi H, Nitta A, Chen W, Nabeshima T. The allosteric potentiation of nicotinic acetylcholine receptors by galantamine ameliorates the cognitive dysfunction in beta amyloid25-35 i.c.v.-injected mice: involvement of dopaminergic systems. Neuropsychopharmacology. 2007;32(6):1261-71. PMID: 17133263.

14. Pichat P, Bergis OE, Terranova JP, Urani A, Duarte C, Santucci V, Gueudet C, Voltz C, Steinberg R, Stemmelin J, Oury-Donat F, Avenet P, Griebel G, Scatton B. SSR180711, a novel selective alpha7 nicotinic receptor partial agonist: (II) efficacy in experimental models predictive of activity against cognitive symptoms of schizophrenia. Neuropsychopharmacology. 2007;32(1):17-34. PMID: 16936709.

15. Sadigh-Eteghad S, Talebi M, Mahmoudi J, Babri S, Shanehbandi D. Selective activation of alpha nicotinic acetylcholine receptor by PHA-543613 improves Abeta-mediated cognitive deficits in mice. Neuroscience. 2015;298:81-93. PMID: 25881725.

16. Franklin KB, Paxinos G. The mouse brain in stereotaxic coordinates. New York: Academic press; 2008.

17. Niwa K, Carlson GA, Iadecola C. Exogenous A beta1-40 reproduces cerebrovascular alterations resulting from amyloid precursor protein overexpression in mice. J Cereb Blood Flow Metab. 2000;20(12):1659-68. PMID: 11129782.

18. Antunes M, Biala G. The novel object recognition memory: neurobiology, test procedure, and its modifications. Cogn Process. 2012;13(2):93-110. PMID: 22160349.

19. Squire LR, Stark CE, Clark RE. The medial temporal lobe. Annu Rev Neurosci. 2004;27:279-306. PMID: 15217334.

20. Sabuncu MR, Desikan RS, Sepulcre J, Yeo BT, Liu H, Schmansky NJ, Reuter M, Weiner MW, Buckner RL, Sperling RA, Fischl B; Alzheimer's Disease Neuroimaging Initiative. The dynamics of cortical and hippocampal atrophy in Alzheimer disease. Arch Neurol. 2011;68(8):1040-8. PMID: 21825241.

21. Roncarati R, Scali C, Comery TA, Grauer SM, Aschmi S, Bothmann H, Jow B, Kowal D, Gianfriddo M, Kelley C, Zanelli U, Ghiron C, Haydar S, Dunlop J, Terstappen GC. Procognitive and neuroprotective activity of a novel alpha7 nicotinic acetylcholine receptor agonist for treatment of neurodegenerative and cognitive disorders. J Pharmacol Exp Ther. 2009;329(2):459-68. PMID: 19223665.

22. Boess FG, De Vry J, Erb C, Flessner T, Hendrix M, Luithle J, Methfessel C, Riedl B, Schnizler K, van der Staay FJ, van Kampen M, Wiese WB, Koenig G. The novel alpha7 nicotinic acetylcholine receptor agonist N-[(3R)-1-azabicyclo[2.2.2]oct-3yl]-7-[2-(methoxy)phenyl]-1-benzofuran-2-carboxa mide improves working and recognition memory in rodents. J Pharmacol Exp Ther. 2007;321(2):716-25. PMID: 17308038.

23. McLean SL, Grayson B, Idris NF, Lesage AS, Pemberton DJ, Mackie C, Neill JC. Activation of alpha7 nicotinic receptors improves phencyclidine-induced deficits in cognitive tasks in rats: implications for therapy of cognitive dysfunction in schizophrenia. Eur Neuropsychopharmacol. 2011;21(4):333-43. PMID: 20630711.

24. Tinsley CJ, Fontaine-Palmer NS, Vincent M, Endean EP, Aggleton JP, Brown MW, Warburton EC. Differing time dependencies of object recognition memory impairments produced by nicotinic and muscarinic cholinergic antagonism in perirhinal cortex. Learn Mem. 2011;18(7):484-92. PMID: 21693636.

25. Callahan PM, Hutchings EJ, Kille NJ, Chapman JM, Terry AV, Jr. Positive allosteric modulator of alpha7 nicotinic-acetylcholine receptors, PNU-120596 augments the effects of donepezil on learning and memory in aged rodents and non-human primates. Neuropharmacology. 2013;67:201-12. PMID: 23168113.

26. Nicolakakis N, Hamel E. Neurovascular function in Alzheimer's disease patients and experimental models. J Cereb Blood Flow Metab. 2011;31(6):1354-70. PMID: 21468088.

27. Badhwar A, Lerch JP, Hamel E, Sled JG. Impaired structural correlates of memory in Alzheimer's disease mice. Neuroimage Clin. 2013;3:290-300. PMID: 24273714.

28. Si ML, Lee TJ. Alpha7-nicotinic acetylcholine receptors on cerebral perivascular sympathetic nerves mediate choline-induced nitrergic neurogenic vasodilation. Circ Res. 2002;91(1):62-9. PMID: 12114323.

29. Rosengarten B, Paulsen S, Molnar S, Kaschel R, Gallhofer B, Kaps M. Acetylcholine esterase inhibitor donepezil improves dynamic cerebrovascular regulation in Alzheimer patients. J Neurol. 2006;253(1):58-64. PMID: 16096820.

30. Bar KJ, Boettger MK, Seidler N, Mentzel HJ, Terborg C, Sauer H. Influence of galantamine on vasomotor reactivity in Alzheimer's disease and vascular dementia due to cerebral microangiopathy. Stroke. 2007;38(12):3186-92. PMID: 17962592.

\section{Correspondence:}

\section{Mahnaz Talebi}

P.O. Box: 5166614756, Tabriz, Iran

Phone/Fax: +984133351227

Mahnaz.Talebi511@gmail.com

Received: July 07, 2015

Review: Sep 09, 2015

Accepted: Oct 05, 2015

Conflict of interest: none

Financial source: Neurosciences Research Center (NSRC) (Grant number: 5.88.1773)

${ }^{1}$ Research performed at Neurosciences Research Center (NSRC), Tabriz University of Medical Sciences, Tabriz, Iran. 